\title{
Assessment of High Risk for Alzheimer's Disease Using Plasma Biomarkers in Subjects with Normal Cognition in Taiwan: A Preliminary Study
}

Chaur-Jong Hu ${ }^{\mathrm{a}, \mathrm{b}, \mathrm{c}, \mathrm{d}}$, Ming-Jang Chiue ${ }^{\mathrm{e}, \mathrm{f}, \mathrm{g}, \mathrm{h}}$, Ming-Chyi Pai ${ }^{\mathrm{i}}$, Sui-Hing Yan ${ }^{\mathrm{j}}$, Pei-Ning Wangk, ${ }^{\mathrm{k}, \mathrm{m}}$, Pai-Yi Chiu ${ }^{\mathrm{n}, \mathrm{o}}$, Chin-Hsien Lin ${ }^{\mathrm{e}}$, Ta-Fu Chen ${ }^{\mathrm{e}}$, Fu-Chi Yang ${ }^{\mathrm{p}}$, Kuo-Lun Huang ${ }^{\mathrm{q}}$, Yi-Ting Hsur ${ }^{\mathrm{r}}$, Yi-Chou Hou ${ }^{\mathrm{s}, \mathrm{t}, \mathrm{u}}$, Wei-Che Lin ${ }^{\mathrm{v}}$, Cheng-Hsien Luw ${ }^{\mathrm{w}}$, Li-Kai Huang ${ }^{\mathrm{a}, \mathrm{b}}$ and Shieh-Yueh Yang ${ }^{\mathrm{x}, *}$ ${ }^{a}$ Department of Neurology, School of Medicine, College of Medicine, Taipei Medical University, Taipei, Taiwan

${ }^{\mathrm{b}}$ Department of Neurology, Dementia Center, Shuang Ho Hospital, Taipei Medical University, New Taipei City, Taiwan

${ }^{\mathrm{c}}$ Graduate Institute of Neural Regenerative Medicine, College of Medical Science and Technology, Taipei Medical University, Taipei, Taiwan

${ }^{\mathrm{d}}$ Taipei Neuroscience Institute, Taipei Medical University, Taipei, Taiwan

${ }^{\mathrm{e}}$ Department of Neurology, National Taiwan University Hospital, College of Medicine,

National Taiwan University, Taipei, Taiwan

${ }^{\mathrm{f}}$ Graduate Institute of Brain and Mind Sciences, College of Medicine, National Taiwan University, Taipei, Taiwan ${ }^{\mathrm{g}}$ Department of Psychology, National Taiwan University, Taipei, Taiwan

${ }^{\mathrm{h}}$ Graduate Institute of Biomedical Electronics and Bioinformatics, National Taiwan University, Taipei, Taiwan ${ }^{\mathrm{i}}$ Division of Behavioral Neurology, Department of Neurology, National Cheng Kung University Hospital, College of Medicine, National Cheng Kung University, Tainan, Taiwan ${ }^{\mathrm{j}}$ Department of Neurology, Far Eastern Memorial Hospital, New Taipei City, Taiwan

${ }^{\mathrm{k}}$ Department of Neurology, Neurological Institute, Taipei Veterans General Hospital, Taipei, Taiwan

${ }^{1}$ Department of Neurology, School of Medicine, National Yang-Ming University, Taipei, Taiwan

${ }^{\mathrm{m}}$ Brain Research Center, National Yang-Ming University, Taipei, Taiwan

${ }^{\mathrm{n}}$ Department of Neurology, Show Chwan Memorial Hospital, Chunghwa, Taiwan

${ }^{\circ}$ MR-guided Focus Ultrasound Center, Chang Bin Show Chwan Memorial Hospital, Chunghwa, Taiwan ${ }^{\mathrm{p}}$ Department of Neurology, Tri-Service General Hospital, National Defense Medical Center, Taipei, Taiwan ${ }^{\mathrm{q}}$ Department of Neurology, Linkou Chang Gung Memorial Hospital, and College of Medicine, Chang Gung University, Taoyuan, Taiwan

${ }^{\mathrm{r}}$ Department of Neurology, China Medical University Hospital, China Medical University, Taichung, Taiwan ${ }^{\mathrm{s}}$ Graduate Institute of Clinical Medicine, College of Medicine, Taipei Medical University, Taipei, Taiwan ${ }^{\mathrm{t}}$ Department of Internal Medicine, Cardinal Tien Hospital, New Taipei City, Taiwan

" School of Medicine, Fu Jen Catholic University, New Taipei City, Taiwan

${ }^{\mathrm{v}}$ Department of Diagnostic Radiology, Kaohsiung Chang Gung Memorial Hospital, Chang Gung University College of Medicine, Kaohsiung, Taiwan

\footnotetext{
*Correspondence to: Shieh-Yueh Yang, MagQu Co., Ltd., New

Taipei City 231, Taiwan. E-mail: syyang@magqu.com.
} 
${ }^{\mathrm{w}}$ Department of Neurology, Kaohsiung Chang Gung Memorial Hospital, Chang Gung University College of Medicine, Kaohsiung, Taiwan

${ }^{\mathrm{x}}$ MagQu Co., Ltd., New Taipei City, Taiwan

Accepted 7 September 2021

Pre-press 30 September 2021

\begin{abstract}
.
Background: In Alzheimer's disease (AD), cognitive impairment begins 10-15 years later than neurodegeneration in the brain. Plasma biomarkers are promising candidates for assessing neurodegeneration in people with normal cognition. It has been reported that subjects with the concentration of plasma amyloid- $\beta 1-42 \times$ total tau protein higher than $455 \mathrm{pg}^{2} / \mathrm{ml}^{2}$ are assessed as having a high risk of amnesic mild impairment or AD, denoted as high risk of AD (HRAD).

Objective: The prevalence of high-risk for dementia in cognitively normal controls is explored by assaying plasma biomarkers. Methods: 422 subjects with normal cognition were enrolled around Taiwan. Plasma A $\beta_{1-40}$, A $\beta_{1-42}$, and T-Tau levels were assayed using immunomagnetic reduction to assess the risk of dementia.

Results: The results showed that $4.6 \%$ of young adults (age: $20-44$ years), $8.5 \%$ of middle-aged adults (age: $45-64$ years), and $7.3 \%$ of elderly adults (age: $65-90$ years) had HRAD. The percentage of individuals with HRAD dramatically increased in middle-aged and elderly adults compared to young adults.

Conclusion: The percentage of HRAD in cognitively normal subjects are approximately $10 \%$, which reveals that the potentially public-health problem of $\mathrm{AD}$ in normal population. Although the subject having abnormal levels of $\mathrm{A} \beta$ or tau is not definitely going on to develop cognitive declines or $\mathrm{AD}$, the risk of suffering cognitive impairment in future is relatively high. Suitable managements are suggested for these high-risk cognitively normal population. Worth noting, attention should be paid to preventing cognitive impairment due to $\mathrm{AD}$, not only in elderly adults but also middle-aged adults.
\end{abstract}

Keywords: Alzheimer's disease, immunomagnetic reduction, normal cognition, plasma biomarkers

\section{INTRODUCTION}

The prevalence of dementia in elderly people $(\geq 65$ years) in Taiwan increased from 2\% in 1995 to $8 \%$ in 2014, and most dementia patients had Alzheimer's disease (AD) [1-4]. The main method of diagnosis for dementia in the clinic in Taiwan is neuropsychological tests and structural neuroimaging examinations [5]. As reported, the onset of cognitive impairment occurs 10-15 years later than the initiation of amyloid accumulation or neurofibrillation in the brain [6]. This implies that clinically cognitively normal subjects might suffer the risk of amyloid accumulation or neurofibrillation. Cognitively normal subjects with amyloid accumulation or neurofibrillation could be assessed as having a high risk for AD (HRAD). It is important to identify HRAD patients because interventions or management could be applied to delay or prevent cognitive impairment in HRAD patients. Thus, the prevalence of dementia could be effectively lowered.

Amyloid positron emission tomography (PET) is a powerful tool to observe pathological evidence of HRAD [7, 8]. Due to its high cost and low availability, amyloid PET is not practically applied to screen HRAD. The changes in the levels of biomarkers such as amyloid- $\beta$ and tau protein in cerebrospinal fluid (CSF) could reflect the amyloid accumulation or neurofibrillation [9-11]. The detection of biomarkers in CSF is suggested to be an alternative way to identify HRAD [9-11]. However, lumbar puncture is an invasive process, and its potential side effects limit the clinical practice of CSF biomarker assays [12, 13].

In recent years, with the successful development of ultrahigh-sensitivity assay technologies, the precise quantitative detection of $\mathrm{AD}$-related biomarkers such as amyloid- $\beta$ 1-40 $\left(A \beta_{1-40}\right), A \beta_{1-42}$, and total tau protein (T-Tau) in blood has become feasible [14-19]. Lots of clinical evidence for validating the uses of plasma $A \beta_{1-40}, A \beta_{1-42}$, and $T$-Tau for assessing the cognitive impairment were reported [20, 21]. The associations between plasma-biomarker assays and current diagnosis of AD were demonstrated [22-24]. For example, the correlations between plasma $A \beta_{1-42}$ or T-Tau and CSF $A \beta_{1-42}$ or T-Tau were revealed [25-27]. This implies that peripheral circulating $A \beta_{1-42}$ and T-Tau reflect the levels of $A \beta_{1-42}$ and $\mathrm{T}$-Tau in central neurological system. Furthermore, the concentration ratio of $A \beta_{1-42}$ to $A \beta_{1-40-}$ in plasma was found to be related to standardized uptake value ratios of amyloid PET [28-30]. Thus, plasma $A \beta_{1-42}$-to- $A \beta_{1-40}$ ratio significantly represents the 
deposition of amyloid in brain. Clinical validations using plasma biomarkers for the assessments of $\mathrm{AD}$ were performed in Taiwan from 2011 to 2016 [31, 32]. According to reports [31, 32], normal controls have the lowest levels of plasma $A \beta_{1-42}$ or T-Tau, which becomes higher in amnestic mild cognitive impairment (aMCI) or AD. The results show that the cut-off value in terms of plasma $A \beta_{1-42} \times \mathrm{T}$-Tau for assessing aMCI or AD is $455 \mathrm{pg}^{2} / \mathrm{ml}^{2}$ [24]. The agreement between plasma biomarker diagnosis and clinical diagnosis is higher than $80 \%$. Such cut-off value is helpful to identify HRAD in normal subjects. Besides, it was found that the concentration of plasma T-Tau negatively correlated to Mini-Mental State Examination (MMSE) scores in aMCI or AD [33]. Concentrations of plasma $A \beta_{1-42-}$ is promisingly an index for predicting the cognitive decline in aMCI $[34,35]$. All the reported results demonstrate the feasibility of assessing the risk of aMCI or $\mathrm{AD}$, monitoring the cognitive impairment in aMCI or $\mathrm{AD}$, and predicting the cognitive decline in aMCI using plasma $A \beta_{1-40}, A \beta_{1-42}$ and T-Tau.

In [31], the subjects were divided into three groups: normal controls (NC), aMCI, and AD according to NIA-AA guidelines. Meanwhile, the plasma $A \beta_{1-40}, A \beta_{1-42}$, and $T-T a u$ were assayed blindly using IMR. After unblinding the results, the values of $A \beta_{1-42} \times \mathrm{T}-\mathrm{Tau}$ were found to be relatively low than those in aMCI and AD. Through RCO curve analysis, the cut-off value to discriminate aMCI/AD from $\mathrm{NC}$ was found to be $455 \mathrm{pg}^{2} / \mathrm{ml}^{2}$, having clinical sensitivity of 0.96 and specificity of 0.97 . The results demonstrate the high accuracy to differentiate aMCI/AD from normal controls by utilizing plasma $\mathrm{A} \beta_{1-42} \times \mathrm{T}-\mathrm{Tau}$ as an assessment parameter for (cutoff value $=455 \mathrm{pg}^{2} / \mathrm{ml}^{2}$ ) aMCI/AD. Although there are other published papers proposing cut-off values of 382 or $400 \mathrm{pg}^{2} / \mathrm{ml}^{2}$, the clinical sensitivity and specificity are not as high as those in [31]. Therefore, in this study, the reported cut-off value $455 \mathrm{pg}^{2} / \mathrm{ml}^{2}$ is cited for assessing the risk for $\mathrm{AD}$. The subjects showing plasma $\mathrm{A} \beta_{1-42} \times \mathrm{T}$-Tau higher than $455 \mathrm{pg}^{2} / \mathrm{ml}^{2}$ were referred to as having a high risk for aMCI or $\mathrm{AD}$, denoted as HRAD, while the subjects showing plasma $A \beta_{1-42}$ x T-Tau between 455 and $382 \mathrm{pg}^{2} / \mathrm{ml}^{2}$ were referred to as being subhealthy subjects.

The assay kits for plasma $A \beta_{1-40}, A \beta_{1-42}$, and TTau utilizing immunomagnetic reduction (IMR) have been approved by the Taiwan Food and Drug Administration. With the approved kits, it is convenient to explore the prevalence of HRAD in cognitively normal subjects via blood testing. In this work, kits were used to assay plasma $A \beta_{1-40}, A \beta_{1-42}$, and T-Tau levels in clinically cognitively normal subjects aged 20 to 89 years, in order to explore the prevalence of HRAD.

\section{MATERIALS AND METHODS}

\section{Recruitment of subjects}

Four hundred and twenty-two subjects were enrolled at eleven hospitals in major cities around Taiwan, such as Taipei, New Taipei, and Taoyuan in northern Taiwan, Taichung and Changhua in central Taiwan, and Tainan and Kaohsiung in southern Taiwan. Each subject was evaluated for past medical history, physical and neurological examinations, and laboratory tests. All subjects were examined with Mini-Mental State Examination (MMSE) and Clinical Dementia Rating (CDR). The score of CSD referred as the global score of CDR in this study. For subjects with suspicious aMCI, tests of Activities of Daily Living (ADL), Instrumental ADL (IADL), or Wechsler Memory Scale III (WMS-III) were performed. Participants with cardiac failure, end-stage renal disease, HbA1c $>8.5$, or Geriatric Depression Scale (GDS) $>8$ were excluded. All enrolled subjects were diagnosed as cognitively normal according to NIA-AA 2011 guidelines [5]. All participants provided written informed consent prior to study enrollment. The data of this study were collected from eleven hospitals that were approved by their institutional review boards.

\section{Plasma preparation}

For IMR measurements, the well-defined protocol of plasma preparation is proposed. A 6-ml EDTA blood collection tube was used for blood draw. The blood was centrifuged at a speed ranging from $1500-2500 \mathrm{~g}$ for $15 \mathrm{~min}$ at room temperature with the aid of a swing-bucket rotor. Notably, the centrifugation was finished no later than $4.5 \mathrm{~h}$ after the blood draw [36]. In addition, the blood tube was at room temperature during the period between blood draw and centrifugation. The plasma in the EDTA tube was transferred and aliquoted into $0.5-\mathrm{ml}$ microcentrifuge tubes and stored at $-80^{\circ} \mathrm{C}$ until biomarker assays. Plasma was frozen no later than $4.5 \mathrm{~h}$ after blood draw. Collected plasma samples were delivered to MagQu Co., Ltd. in New Taipei City, Taiwan, with a dry-ice package for blind assays of plasma biomarkers. 


\section{Assays of plasma biomarkers}

Plasma biomarkers were assayed with IMR. Different IMR kits (MF-AB0-0060, MF-AB2-0060, MF-TAU-0060, MagQu) and an IMR analyzer (XacPro-S, MagQu) were used for assaying $A \beta_{1-40}$, $A \beta_{1-42}$, and T-Tau. The pre-clinical performances of IMR $A \beta_{1-40}, A \beta_{1-42}$, and T-Tau were published [27, 37]. Duplicated measurements were conducted for each biomarker per sample. The mean value of the duplicated measurements was reported for every individual biomarker of a subject. IMR measurements for $\mathrm{A} \beta_{1-40}, A \beta_{1-42}$, and T-Tau were performed by following the manufactures' instructions described in package inserts.

\section{Statistical methods}

Continuous variables for each measurement are presented as the mean \pm standard deviation. Continuous variables were compared using $t$-tests, and the $p$ values were determined. The analysis of Pearson correlation, r, was performed with GraphPad Prism.

\section{Distribution of biomarker concentrations}

For a given biomarker, the concentration distributions was analyzed by fitting the measured results to the Gaussian distribution as expressed

$$
\text { Portion }(\%)=\mathrm{A}_{\mathrm{o}} \exp \left(-0.5 \mathrm{x}\left(\frac{\phi-\bar{\phi}}{\sigma}\right)^{2}\right) \text {, }
$$

where $A_{o}$ is the amplitude of the distribution $\phi$ is the concentration of plasma biomarker, $\bar{\phi}$ and $\sigma$ are the mean value and the standard deviation of the distribution in concentration, respectively.

\section{RESULTS}

There were 255 female and 167 male subjects enrolled in this study. The ages of the enrolled subjects ranged from 20 to 89 years. The numbers of enrolled female and male subjects in young adults (20-44 years), middle-aged adults (MA, 45-64 years), and old adults (OA, $\geq 65$ years) are listed in Table 1 . The percentage of was approximately $10 \%$, MA was almost 50\%, and OA was approximately $40 \%$ in this study.

Brief demographics is listed in Table 2. The average ages were $60.5 \pm 12.2$ years for females and $62.4 \pm 14.2$ years for males. The average age of all
Table 1

Numbers of enrolled female and male subjects at various age ranges

\begin{tabular}{lccc}
\hline Group & $\begin{array}{c}\text { Female, } \\
n(\%)\end{array}$ & $\begin{array}{c}\text { Male, } \\
n(\%)\end{array}$ & $\begin{array}{c}\text { All, } \\
n(\%)\end{array}$ \\
\hline Age (y) & & & \\
$20-44$ (young adults) & $23(9.02)$ & $20(11.98)$ & $43(10.19)$ \\
45-64 (middle-aged & $135(52.94)$ & $66(39.52)$ & $201(47.63)$ \\
adults) & & & \\
$\geq 65$ (old adults) & $97(38.04)$ & $81(48.50)$ & $178(42.18)$ \\
Total & 255 & 167 & 422 \\
\hline
\end{tabular}

Table 2

Demographics of enrolled subjects

\begin{tabular}{|c|c|c|c|}
\hline Group & Female & Male & All \\
\hline $\bar{n}$ & 255 & 167 & 422 \\
\hline Age (y) & $60.5 \pm 12.2$ & $62.4 \pm 14.2$ & $61.2 \pm 13.0$ \\
\hline Education & & $\geq 6 y$ & \\
\hline $\mathrm{CDR}$ & 0 & 0 & 0 \\
\hline MMSE & & $\geq 28$ & \\
\hline $\mathrm{A} \beta_{1-40}(\mathrm{pg} / \mathrm{ml})$ & $56.52 \pm 11.67$ & $57.41 \pm 15.10$ & $56.9 \pm 13.1$ \\
\hline $\mathrm{A} \beta_{1-42}(\mathrm{pg} / \mathrm{ml})$ & $15.64 \pm 2.21$ & $15.81 \pm 2.00$ & $15.71 \pm 2.13$ \\
\hline T-Tau (pg/ml) & $19.37 \pm 7.07$ & $20.19 \pm 6.23$ & $19.69 \pm 6.75$ \\
\hline $\begin{array}{c}\mathrm{A} \beta_{1-42} \times \mathrm{T}-\mathrm{Tau} \\
\left(\mathrm{pg}^{2} / \mathrm{ml}^{2}\right)\end{array}$ & $309.9 \pm 145.5$ & $327.7 \pm 148.0$ & $316.9 \pm 146.6$ \\
\hline $\mathrm{A} \beta_{1-42} / \mathrm{A} \beta_{1-40}$ & $0.288 \pm 0.080$ & $0.291 \pm 0.087$ & $0.289 \pm 0.083$ \\
\hline
\end{tabular}

CDR, the global score of Clinical Dementia Rating; MMSE, MiniMental State Examination; $A \beta$, amyloid- $\beta$; T-Tau, total tau protein.

subjects was $61.2 \pm 13.0$ years. The education of each subject is more than 6 years. The clinical dementia ranking score was zero, and the MMSE score was higher than 28 for every individual. Thus, all enrolled subjects were cognitively normal. In addition, there was no movement disorder or language disorder in any subject. Therefore, from the phenotype point of view, all enrolled subjects were nondemented and normal controls. APOE genotype is not analyzed in this study.

The mean measured $A \beta_{1-40}$ concentrations in plasma for females were $56.52 \pm 11.67 \mathrm{pg} / \mathrm{ml}, 57.41 \pm$ $15.10 \mathrm{pg} / \mathrm{ml}$ for males, and $56.9 \pm 13.1 \mathrm{pg} / \mathrm{ml}$ for all subjects. There was no significant difference in plasma $A \beta_{1-40}$ levels between females and males ( $p>0.05)$. Regarding plasma $\mathrm{A} \beta_{1-42}$, females had $15.64 \pm 2.21 \mathrm{pg} / \mathrm{ml}$, males had $15.81 \pm 2.00 \mathrm{pg} / \mathrm{ml}$, and all subjects had $15.71 \pm 2.13 \mathrm{pg} / \mathrm{ml}$. Through $t$-test analysis, the $p$ value between females and males for plasma $A \beta_{1-42}$ levels was higher than 0.05 . This reveals that the plasma $A \beta_{1-42}$ level is sex independent. Notably, the average plasma $A \beta_{1-42}$ concentrations in females and males were lower than the cutoff level $(=16.33-17.22 \mathrm{pg} / \mathrm{ml})$ in discriminating amnesic mild cognitive impairment (aMCI) and $\mathrm{AD}[31,32,38]$. This evidence indicates that 
(a)

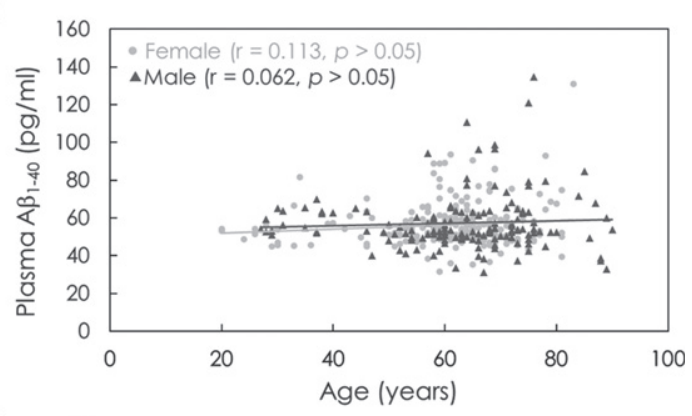

(b)

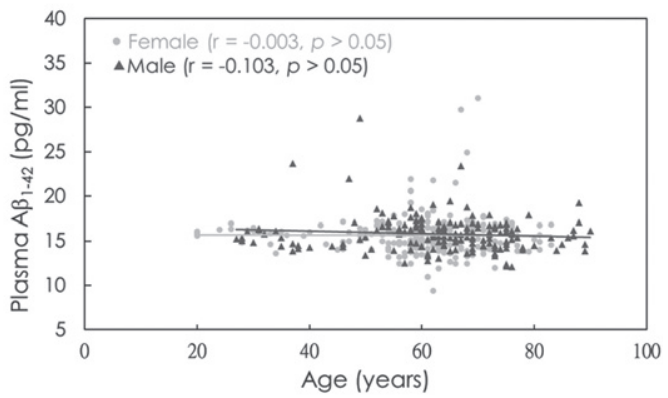

(c)

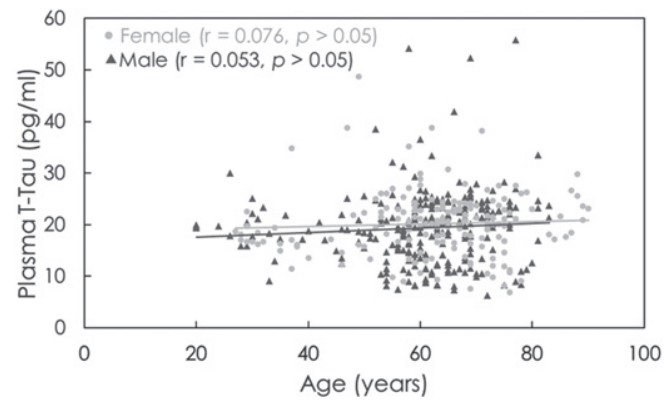

Fig. 1. Age-dependent concentrations of plasma (a) $A \beta_{1-40}$, (b) $A \beta_{1-42}$, and (c) T-Tau in females (gray dots) and males (dark gray dots).

the recruited cohort in this study was a normal control. However, some individuals have plasma $A \beta_{1-42}$ concentrations higher than the cutoff level.

For plasma T-Tau concentrations, the female was $19.37 \pm 7.07 \mathrm{pg} / \mathrm{ml}$, the male was $20.19 \pm 6.23 \mathrm{pg} /$ $\mathrm{ml}$, and all subjects had $19.69 \pm 6.75 \mathrm{pg} / \mathrm{ml}$. Similar to $A \beta_{1-40}$ and $A \beta_{1-42}$, there was no significant difference in plasma T-Tau levels between females and males $(p>0.05)$. According to reported papers, the cutoff level of differentiating aMCI and $\mathrm{AD}$ from normal controls is $21.3-25.41 \mathrm{pg} / \mathrm{ml}$ [31, 32, 38, 39]. The cutoff level was obviously higher than the averaged values in females and males. This also shows that the enrolled cohort is a normal control.

The biomarker concentrations of $A \beta_{1-40}, A \beta_{1-42}$, and T-Tau as functions of age are shown in Fig. 1a-c. The Pearson correlation $\mathrm{r}$ and $t$-test $p$ value between the biomarker concentration and age were analyzed, as labeled in Fig. 1a-c. In both females and males, there was no significant correlation between age and plasma $\mathrm{A} \beta_{1-40}, \mathrm{~A} \beta_{1-42}$, or T-Tau $(r=-0.103-$ $0.113 ; p>0.05)$. This implies that the concentrations of plasma $A \beta_{1-40}, A \beta_{1-42}$, and T-Tau in cognitively normal controls are age independent from 20 to 89 years. This is consistent with the results reported in a previous paper [40].

Figure $1 \mathrm{~b}$ and $1 \mathrm{c}$ show that there are some subjects showing higher concentrations of plasma $A \beta_{1-42}$ or T-Tau. According to reported papers [27, 31, 32, 38, 39], the levels of plasma $A \beta_{1-42}$ and T-Tau measured with IMR are elevated in $\mathrm{AMCI}$ and $\mathrm{AD}$ patients compared with normal controls. The levels of plasma $\mathrm{A} \beta_{1-42} \times \mathrm{T}$-Tau have been demonstrated to be an index for assessing the risk of aMCI and AD and have been approved in clinical uses in Europe and Taiwan. The cutoff value of plasma $A \beta_{1-42} \times$ T-Tau to discriminate aMCI and AD from normal controls was demonstrated to range from 382 to $455 \mathrm{pg}^{2} / \mathrm{ml}^{2}$ [31, $32,38,39]$. The difference in the cutoff levels among reports might be due to several possible causes, such as AD severity of enrolled subjects and subjective comments on neuropsychological tests.

All subjects were enrolled at 11 hospitals in Taiwan. The enrolled numbers of subject are not consistent among hospitals. For example, there were 151 subjects enrolled at National Taiwan University Hospital (NTNU), but only 11 subjects at Taipei City Hospital-Ren-Ai Branch. Instead of 11 hospitals, we divided all sites into three parties: NTNU, hospitals in north Taiwan (North, 6 hospitals), and hospitals in middle and south Taiwan (Middle-to-South, 4 hospitals). The enrolled subjects are 151 in NTNU, 141 in North and 130 in Middle-to-South. The enrolled numbers of subjects are close to each other among NTNU, North and Middle-to-South. The ages, levels of plasma $A \beta_{1-40}, A \beta_{1-42}$, T-Tau, and $A \beta_{1-42} \times$ T-Tau are listed in Table 3.

Through one-way ANOVA analysis, significant differences in age, plasma $A \beta_{1-40}$ concentrations and $A \beta_{1-42}$ concentrations among NTNU, North and Middle-to-South. Plasma T-Tau and $\mathrm{A} \beta_{1-42}$ x T-Tau concentrations show no significant difference among NTNU, North and Middle-to-South. Thus, plasma $\mathrm{A} \beta_{1-42} \times \mathrm{T}-\mathrm{Tau}$ was used as a parameter to assess the risk of $\mathrm{AD}$ in this study.

The percentages of HRAD and subhealth in females and males in young adults (YA, 20-44 years), middle-aged adults (MA, 45-64 years), and old adults $(\mathrm{OA}, \geq 65$ years) were analyzed. 
Table 3

Measured concentrations of plasma $A \beta_{1-40}, A \beta_{1-42}$, and T-Tau in three territories of 11 hospitals joining this study

\begin{tabular}{|c|c|c|c|c|}
\hline Item & NTUH & North* & Middle-to-South ${ }^{+}$ & $p$ \\
\hline$n$ (female $\%)$ & $151(55.6 \%)$ & $141(59.6 \%)$ & $130(66.9 \%)$ & - \\
\hline Age (y) & $62.9 \pm 15.1$ & $64.5 \pm 7.1$ & $55.7 \pm 13.8$ & $<0.0001$ \\
\hline $\mathrm{A} \beta_{1-40}(\mathrm{pg} / \mathrm{ml})$ & $61.50 \pm 16.39$ & $55.74 \pm 13.05$ & $54.11 \pm 7.99$ & $<0.0001$ \\
\hline $\mathrm{A} \beta_{1-42}(\mathrm{pg} / \mathrm{ml})$ & $15.22 \pm 1.86$ & $15.81 \pm 1.50$ & $16.17 \pm 2.80$ & $<0.001$ \\
\hline $\mathrm{T}-\mathrm{Tau}(\mathrm{pg} / \mathrm{ml})$ & $19.52 \pm 1.86$ & $20.25 \pm 5.93$ & $19.28 \pm 7.71$ & $>0.05$ \\
\hline $\mathrm{A} \beta_{1-42} \times \mathrm{T}-\mathrm{Tau}\left(\mathrm{pg}^{2} / \mathrm{ml}^{2}\right)$ & $302.5 \pm 124.9$ & $324.1 \pm 113.5$ & $325.9 \pm 193.9$ & $>0.05$ \\
\hline
\end{tabular}

$\mathrm{A} \beta$ amyloid- $\beta$; T-Tau, total tau protein; NTNU, National Taiwan University Hospital; *including 6 hospitals in north Taiwan; ${ }^{+}$including 4 hospitals in middle or south Taiwan.

(a)

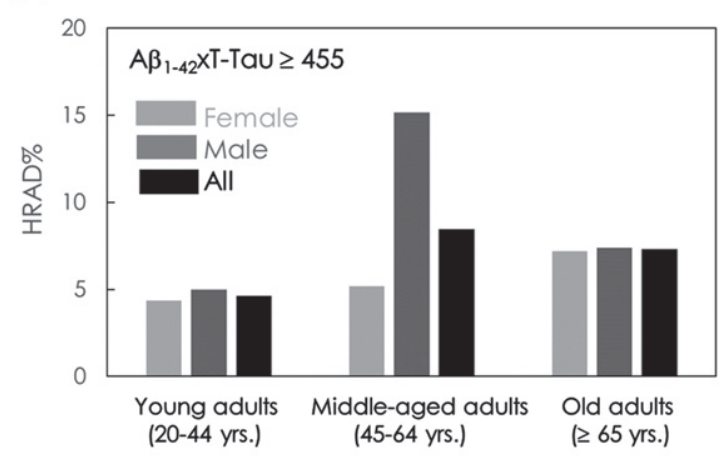

(b)

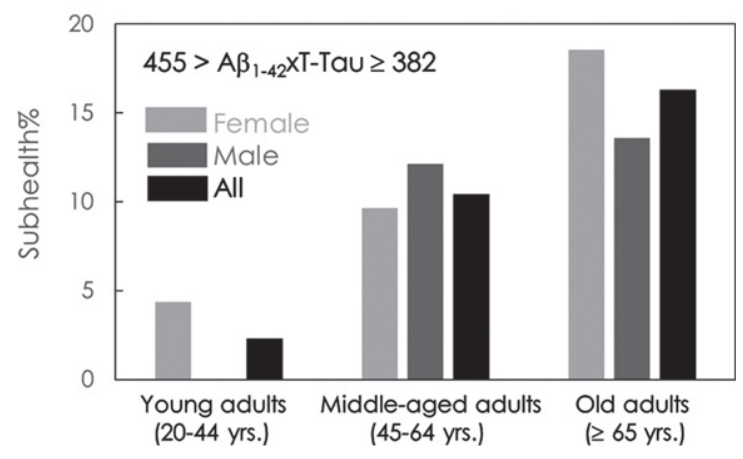

Fig. 2. Percentage of (a) high risk for amnesic mild impairment or $\mathrm{AD}$ (HRAD) and (b) subhealth in cognitively normal subjects in young adults, middle-aged adults and old adults.

As shown in Fig. 2a, $4.35 \%$ of YA, $5.19 \%$ of MA, and $7.22 \%$ of OA among females showed HRAD. Among males, $5.00 \%$ of YA, $15.2 \%$ of MA, and $7.41 \%$ of OA showed HRAD. Overall, $4.65 \%$ of YA, $8.46 \%$ of MA, and $7.30 \%$ of OA in all subjects showed HRAD. The percentage of HRAD in MA was 1.86 times that in YA and in OA was 1.56 times that in YA. A remarkable result is shown in Fig. 2a. MA shows a relatively high percentage for HRAD, especially in males. This group also confers more cardiovascular diseases that result in more AD pathology in midlife and mortality effects on the reduction prevalence of HRAD in male OA. The results in Fig. 2a suggest that attention should be given to preventing cognitive impairment not solely for old adults but also for middle-aged adults.

As mentioned in the Introduction, the prevalence of dementia in the elderly population ( $\geq 65$ years) is $8 \%$ in Taiwan [1-4]. That means $92 \%$ of elderly people are nondemented. With the results shown in Fig. 2a, $7.3 \%$ of cognitively normal aged people have HRAD. As a result, approximately $6.7 \%$ of aged population are HRAD, which is close to that of demented patients.

The percentages of subhealthy individuals in YA, MA, and OA are shown in Fig. 2b. A total of $4.35 \%$ of YA, $9.63 \%$ of MA, and $18.6 \%$ of OA in females were subhealthy. In males, none of the YAs, $12.1 \%$ of MA, and $13.6 \%$ of OA were subhealthy. In all subjects, $2.33 \%$ of YA, $10.4 \%$ of MA, and $16.3 \%$ of $\mathrm{OA}$ were subhealthy. The percentage of subhealthy individuals in the MA group was 4.46 times that in the YA group and 7.00 times that in the OA group. The percentages of subhealthy individuals in MA and OA were dramatically higher than those in YA. The results again suggest that prevention from cognitive impairment should be performed for an individual when he/she becomes middle-aged.

\section{DISCUSSION}

As shown in Fig. 2, in all subjects, the ratio of subhealth to HRAD in terms of subject numbers in YA was 0.5 . The ratio increases to 1.24 in MA and 2.23 in OA. This reveals the fact that the population of subhealthy individuals is higher than that of HRAD individuals in both MA and OA. In OA, the population of subhealth individuals is more than twice that of HRAD patients.

In Fig. 2a, male MA (15.2\%) shows a relatively high percentage of HRAD than female MA (5.19\%). In Fig. 2b, male MA (12.1\%) shows a higher percentage of subhealth than female MA 
Table 4

Values of fitting parameters in Equation (1) for plasma biomarkers $\mathrm{A} \beta_{1-40}, \mathrm{~A} \beta_{1-42}$ and T-Tau

\begin{tabular}{llccc}
\hline Biomarker & Gender & $\mathrm{A}_{o}$ & $\bar{\phi}(\mathrm{pg} / \mathrm{ml})$ & $\sigma(\mathrm{pg} / \mathrm{ml})$ \\
\hline $\mathrm{A} \beta_{1-40}$ & Female & 50.7 & 54.37 & 5.73 \\
& Male & 44.6 & 55.05 & 7.04 \\
$\mathrm{~A} \beta_{1-42}$ & Female & 72.7 & 15.39 & 1.17 \\
& Male & 72.2 & 15.66 & 1.22 \\
T-Tau & Female & 37.4 & 19.20 & 5.71 \\
& Male & 45.6 & 19.82 & 4.35 \\
\hline
\end{tabular}

$\mathrm{A} \beta$, amyloid- $\beta$; T-Tau, total tau protein.

$(9.63 \%)$. The reasons for the high percentage of HRAD and subhealth in male MA are unknown. However, according to published reports [41-44], comorbidities such as diabetes, obesity, cardiovascular disease, or metabolic syndrome are risk factors for dementia. Many groups in Taiwan have shown that the prevalence of these comorbidities is significantly higher in male than in female in midlife [45-47]. This could be the possible reasons for the high percentage of HRAD in male MA found in this study.

The concentration distributions of plasma $A \beta_{1-40}$, $A \beta_{1-42}$, and T-Tau in female and male were analyzed via Equation (1), as shown in Fig. 3a-c. The values of parameters $\mathrm{A}_{\mathrm{o}}, \bar{\phi}$, and $\sigma$ in Equation (1) for plasma $A \beta_{1-40}, A \beta_{1-42}$, and T-Tau are listed in Table 4. The coefficients of determination $\mathrm{R}^{2}$ for all the curves in Fig. 3a-c are higher than 0.9. This reveals the high consistence between the data and the fitted Gaussian distribution. Besides, for a given plasma biomarker, there is no significant deviation in the Gaussian distribution between female and male. Hence, the concentrations of plasma $A \beta_{1-40}, A \beta_{1-42}$, and $\mathrm{T}$-Tau measured with IMR are gender dependent in cognitively normal subjects.

The results in Table 4 showed that the mean value of $A \beta_{1-40}$ concentrations in cognitively normal subjects is $54.37 \mathrm{pg} / \mathrm{ml}$ in female and is $55.05 \mathrm{pg} / \mathrm{ml}$ in male. The mean value of $A \beta_{1-42}$ concentrations in cognitively normal subjects is $15.39 \mathrm{pg} / \mathrm{ml}$ in female and is $15.66 \mathrm{pg} / \mathrm{ml}$ in male. The mean value of $\mathrm{T}$ Tau concentrations in cognitively normal subjects is $19.20 \mathrm{pg} / \mathrm{ml}$ in female and is $19.82 \mathrm{pg} / \mathrm{ml}$ in male. The mean values of plasma concentrations obtained via Equation (1) are close to the values listed in Table 2.

The ratio of $\sigma$ to $\bar{\phi}$ denotes the im-precession of the plasma biomarker concentration span. The ratio was calculated to be approximately $11 \%$ for plasma $A \beta_{1-40}, 7.8 \%$ for $A \beta_{1-42}$, and $25 \%$ for T-Tau. Thus, narrow spans were found for $A \beta_{1-40}$ and $A \beta_{1-42}$, and a moderated span for plasma T-Tau in cognitively normal subjects.
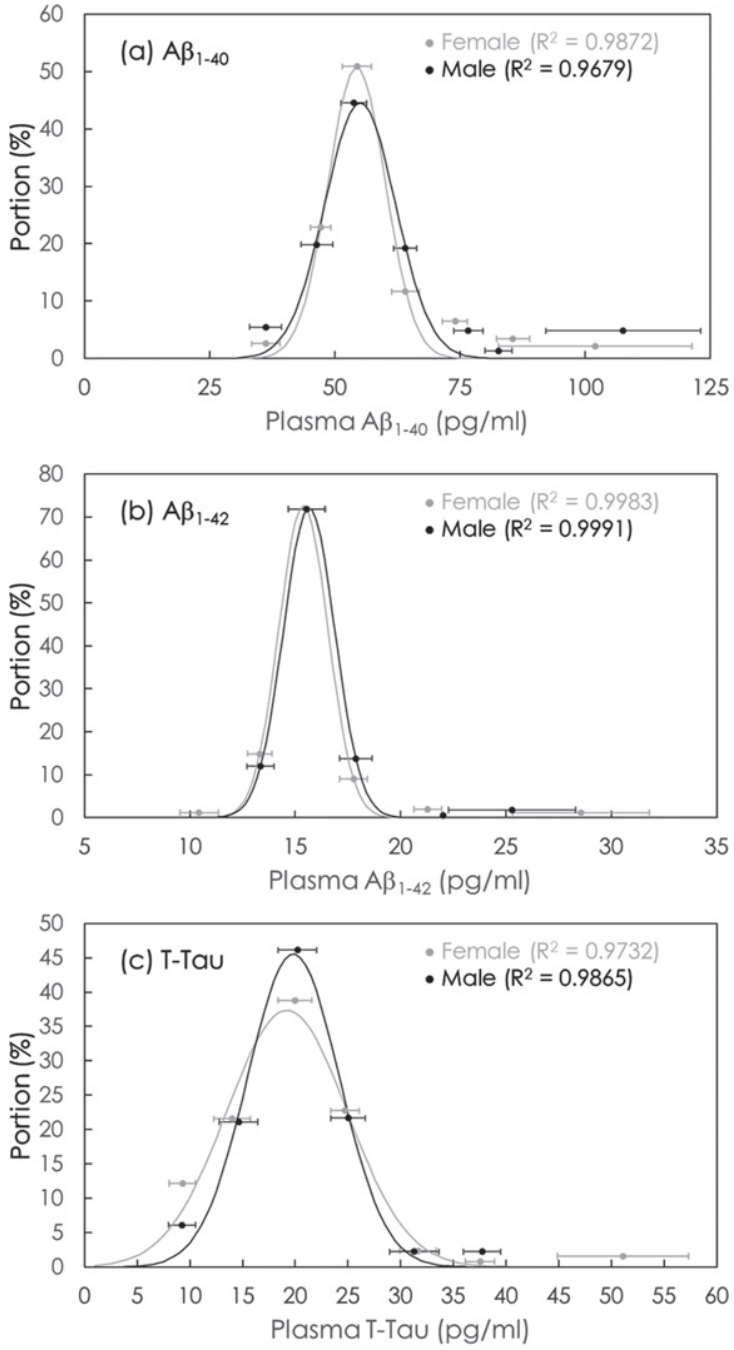

Fig. 3. Gaussian distributions of concentrations of (a) $\mathrm{A} \beta_{1-40}$, (b) $\mathrm{A} \beta_{1-42}$, and (c) T-Tau in plasma in cognitively normal subjects. The solid lines are the fitted Equation (1). The values of fitting parameters are shown in Table 3.

In this study, 422 cognitively normal subjects were enrolled. It would be better to recruit more subjects to validate the percentages of HRAD and subhealth in cognitively normal populations. The results of preliminary study provide direct evidence from the plasma biomarkers that the MA cohort for should be a target of dementia prevention.

\section{CONCLUSION}

The exploration of age-dependent AD-related biomarkers in plasma in clinically cognitive normal controls is very rare. In this study, 422 subjects with normal cognition were enrolled in seven cities around 
Taiwan. The ages of the enrolled subjects ranged from 20 to 89 years. The results show that the concentrations of plasma $A \beta_{1-40}, A \beta-\beta_{-1-42-}$, and T-Tau are age dependent in females and males. There was no significant difference in biomarker levels between females and males. The results reveal that the percentage of subhealth is $13.2 \%$ for individuals who become middle-aged ( $\geq 45$ years). The percentage of subjects that are high risk for aMCI or AD (HRAD) is $7.9 \%$ for individuals who are middle-aged ( $\geq 45$ years). Thus, the data strongly suggest paying attention to not only old adults but also middle-aged adults to prevent cognitive impairment, especially for the middle-aged male.

\section{ACKNOWLEDGMENTS}

We thank the MagQu company (New Taipei City, Taiwan) for providing the immunomagnetic reduction technique for detecting neurological biomarkers in plasma. This work was supported by Taiwan Ministry of Science and Technology under grant numbers 105-2314-B-002-001, 107-2321-B-039004, 106-2314-B-038-001, 107-2314-B-038-050, 108-2314-B-303-029, 109-231-B-002-029.

\section{CONFLICT OF INTEREST}

SY Yang is an employee and a shareholder of MagQu Co., Ltd. Other authors do not have conflicts of interest.

\section{ETHICAL STANDARDS}

The Institutional Review Board of Shuang Ho Hospital, National Taiwan University Hospital, National Cheng Kung University Hospital, Taipei Veterans General Hospital, Show Chwan Memorial Hospital, Tri-Service General Hospital, Linkou Chang Gung Memorial Hospital, China Medical University Hospital, Cardinal Tien Hospital, Taipei City Hospital, Kaohsiung Chang Gung Memorial Hospital, approved this study. Written informed consent was obtained from all patients or their legal guardians.

\section{REFERENCES}

[1] Liu HC, Lin KN, Teng EL, Wang SJ, Fuh JL, Guo NW, Chou P, Hu HH, Chiang BN (1995) Prevalence and subtypes of dementia in Taiwan: A community survey of 5297 individuals. J Am Geriatr Soc 43, 144-149.
[2] Fuh JL, Wang SJ (2008) Dementia in Taiwan: Past, present, and future. Acta Neurol Taiwan 17, 153-161.

[3] Sun Y, Lee HJ, Yang SC, Chen TF, Lin KN, Lin CC, Wang PN, Tang LY, Chiu MJ (2014) A nationwide survey of mild cognitive impairment and dementia, including very mild dementia, in Taiwan. PLoS One 9, e100303.

[4] Liu CC, Li CY, Sun Y, Hu SC (2019) Gender and age differences and the trend in the incidence and prevalence of dementia and Alzheimer's disease in Taiwan: A 7-year national population-based study. Biomed Res Int 2019, 5378540.

[5] McKhann GM, Knopman DS, Chertkow H, Hyman BT, Jack CR, Jr., Kawas CH, Klunk WE, Koroshetz WJ, Manly JJ, Mayeux R, Mohs RC, Morris JC, Rossor MN, Scheltens P, Carrillo MC, Thies B, Weintraub S, Phelps $\mathrm{CH}$ (2011) The diagnosis of dementia due to Alzheimer's disease: Recommendations from the National Institute on Aging-Alzheimer's Association workgroups on diagnostic guidelines for Alzheimer's disease. Alzheimers Dement 7, 263-269.

[6] Jack CR, Jr., Knopman DS, Jagust WJ, Petersen RC, Weiner MW, Aisen PS, Shaw LM, Vemuri P, Wiste HJ, Weigand SD, Lesnick TG, Pankratz VS, Donohue MC, Trojanowski JQ (2013) Tracking pathophysiological processes in Alzheimer's disease: An updated hypothetical model of dynamic biomarkers. Lancet Neurol 12, 207-216.

[7] Vlassenko AG, Benzinger TL, Morris JC (2012) PET amyloid-beta imaging in preclinical Alzheimer's disease. Biochim Biophys Acta 1822, 370-379.

[8] Koscik RL, Betthauser TJ, Jonaitis EM, Allison SL, Clark LR, Hermann BP, Cody KA, Engle JW, Barnhart TE, Stone CK, Chin NA, Carlsson CM, Asthana S, Christian BT, Johnson SC (2020) Amyloid duration is associated with preclinical cognitive decline and tau PET. Alzheimers Dement (Amst) 12, e12007.

[9] de Leon MJ, Mosconi L, Blennow K, DeSanti S, Zinkowski R, Mehta PD, Pratico D, Tsui W, Saint Louis LA, Sobanska L, Brys M, Li Y, Rich K, Rinne J, Rusinek H (2007) Imaging and CSF studies in the preclinical diagnosis of Alzheimer's disease. Ann N Y Acad Sci 1097, 114-145.

[10] Gomar JJ, Conejero-Goldberg C, Davies P, Goldberg TE, Alzheimer's Disease Neuroimaging Initiative (2016) Anticorrelated cerebrospinal fluid biomarker trajectories in preclinical Alzheimer's disease. J Alzheimers Dis 51, 10851097.

[11] Trelle AN, Carr VA, Wilson EN, Swarovski MS, Hunt MP, Toueg TN, Tran TT, Channappa D, Corso NK, Thieu MK, Jayakumar M, Nadiadwala A, Guo W, Tanner NJ, Bernstein JD, Litovsky CP, Guerin SA, Khazenzon AM, Harrison MB, Rutt BK, Deutsch GK, Chin FT, Davidzon GA, Hall JN, Sha SJ, Fredericks CA, Andreasson KI, Kerchner GA, Wagner AD, Mormino EC (2021) Association of CSF biomarkers with hippocampal-dependent memory in preclinical Alzheimer disease. Neurology 96, e1470e1481.

[12] Kruesi MJ, Swedo SE, Coffey ML, Hamburger SD, Leonard H, Rapoport JL (1988) Objective and subjective side effects of research lumbar punctures in children and adolescents. Psychiatry Res 25, 59-63.

[13] Ozdemir HH, Demir CF, Varol S, Arslan D, Yildiz M, Akil E (2015) The effects of needle deformation during lumbar puncture. J Neurosci Rural Pract 6, 198-201.

[14] Xia W, Yang T, Shankar G, Smith IM, Shen Y, Walsh DM, Selkoe DJ (2009) A specific enzyme-linked immunosorbent assay for measuring beta-amyloid protein oligomers in 
human plasma and brain tissue of patients with Alzheimer disease. Arch Neurol 66, 190-199.

[15] Oh ES, Mielke MM, Rosenberg PB, Jain A, Fedarko NS, Lyketsos CG, Mehta PD (2010) Comparison of conventional ELISA with electrochemiluminescence technology for detection of amyloid-beta in plasma. J Alzheimers Dis 21, 769-773.

[16] Birkmann E, Henke F, Weinmann N, Dumpitak C, Groschup M, Funke A, Willbold D, Riesner D (2007) Counting of single prion particles bound to a capture-antibody surface (surface-FIDA). Vet Microbiol 123, 294-304.

[17] Kim JS, Ahn HS, Cho SM, Lee JE, Kim Y, Lee C (2014) Detection and quantification of plasma amyloid-beta by selected reaction monitoring mass spectrometry. Anal Chim Acta 840, 1-9.

[18] Mondello S, Buki A, Barzo P, Randall J, Provuncher G, Hanlon D, Wilson D, Kobeissy F, Jeromin A (2014) CSF and plasma amyloid-beta temporal profiles and relationships with neurological status and mortality after severe traumatic brain injury. Sci Rep 4, 6446.

[19] Chiu MJ, Horng HE, Chieh JJ, Liao SH, Chen CH, Shih BY, Yang CC, Lee CL, Chen TF, Yang SY, Hong CY, Yang HC (2011) Multi-channel SQUID-based ultra-high-sensitivity in-vitro detections for bio-markers of Alzheimer's disease via immunomagnetic reduction. IEEE Trans Appl Supercond 21, 477-480.

[20] Cullen NC, Leuzy A, Janelidze S, Palmqvist S, Svenningsson AL, Stomrud E, Dage JL, Mattsson-Carlgren N, Hansson O (2021) Plasma biomarkers of Alzheimer's disease improve prediction of cognitive decline in cognitively unimpaired elderly populations. Nat Commun 12, 3555.

[21] Mielke MM, Hagen CE, Wennberg AMV, Airey DC, Savica R, Knopman DS, Machulda MM, Roberts RO, Jack CR, Jr., Petersen RC, Dage JL (2017) Association of plasma total tau level with cognitive decline and risk of mild cognitive impairment or dementia in the Mayo Clinic Study on Aging. JAMA Neurol 74, 1073-1080.

[22] Nakamura A, Kaneko N, Villemagne VL, Kato T, Doecke J, Dore V, Fowler C, Li QX, Martins R, Rowe C, Tomita T, Matsuzaki K, Ishii K, Ishii K, Arahata Y, Iwamoto S, Ito K, Tanaka K, Masters CL, Yanagisawa K (2018) High performance plasma amyloid-beta biomarkers for Alzheimer's disease. Nature 554, 249-254.

[23] Deters KD, Risacher SL, Kim S, Nho K, West JD, Blennow K, Zetterberg H, Shaw LM, Trojanowski JQ, Weiner MW, Saykin AJ, Alzheimer Disease Neuroimaging Initiative (2017) Plasma tau association with brain atrophy in mild cognitive impairment and Alzheimer's disease. J Alzheimers Dis 58, 1245-1254.

[24] Ding X, Zhang S, Jiang L, Wang L, Li T, Lei P (2021) Ultrasensitive assays for detection of plasma tau and phosphorylated tau 181 in Alzheimer's disease: A systematic review and meta-analysis. Transl Neurodegener 10, 10.

[25] Palmqvist S, Insel PS, Stomrud E, Janelidze S, Zetterberg H, Brix B, Eichenlaub U, Dage JL, Chai X, Blennow K, Mattsson N, Hansson O (2019) Cerebrospinal fluid and plasma biomarker trajectories with increasing amyloid deposition in Alzheimer's disease. EMBO Mol Med 11, e11170.

[26] Frankfort SV, Tulner LR, van Campen JP, Verbeek MM, Jansen RW, Beijnen JH (2008) Amyloid beta protein and tau in cerebrospinal fluid and plasma as biomarkers for dementia: A review of recent literature. Curr Clin Pharmacol 3, 123-131.

[27] Teunissen CE, Chiu MJ, Yang CC, Yang SY, Scheltens P, Zetterberg H, Blennow K (2018) Plasma amyloid-beta
(Abeta42) correlates with cerebrospinal fluid Abeta42 in Alzheimer's disease. J Alzheimers Dis 62, 1857-1863.

[28] Tzen KY, Yang SY, Chen TF, Cheng TW, Horng HE, Wen HP, Huang YY, Shiue CY, Chiu MJ (2014) Plasma Abeta but not tau is related to brain PiB retention in early Alzheimer's disease. ACS Chem Neurosci 5, 830-836.

[29] Fan LY, Tzen KY, Chen YF, Chen TF, Lai YM, Yen RF, Huang YY, Shiue CY, Yang SY, Chiu MJ (2018) The relation between brain amyloid deposition, cortical atrophy, and plasma biomarkers in amnesic mild cognitive impairment and Alzheimer's disease. Front Aging Neurosci 10, 175

[30] Lin SY, Lin KJ, Lin PC, Huang CC, Chang CC, Lee YC, Hsiao IT, Yen TC, Huang WS, Yang BH, Wang PN (2019) Plasma amyloid assay as a pre-screening tool for amyloid positron emission tomography imaging in early stage Alzheimer's disease. Alzheimers Res Ther 11, 111.

[31] Chiu MJ, Yang SY, Horng HE, Yang CC, Chen TF, Chieh JJ, Chen HH, Chen TC, Ho CS, Chang SF, Liu HC, Hong CY, Yang HC (2013) Combined plasma biomarkers for diagnosing mild cognition impairment and Alzheimer's disease. ACS Chem Neurosci 4, 1530-1536.

[32] Chiu MJ, Chen TF, Hu CJ, Yan SH, Sun Y, Liu BH, Chang YT, Yang CC, Yang SY (2020) Nanoparticle-based immunomagnetic assay of plasma biomarkers for differentiating dementia and prodromal states of Alzheimer's disease - A cross-validation study. Nanomedicine 28, 102182.

[33] Tsai CL, Liang CS, Lee JT, Su MW, Lin CC, Chu HT, Tsai CK, Lin GY, Lin YK, Yang FC (2019) Associations between plasma biomarkers and cognition in patients with Alzheimer's disease and amnestic mild cognitive impairment: A cross-sectional and longitudinal study. J Clin Med 8, 1893.

[34] Chen TB, Lee YJ, Lin SY, Chen JP, Hu CJ, Wang PN, Cheng IH (2019) Plasma Abeta42 and total tau predict cognitive decline in amnestic mild cognitive impairment. Sci Rep $\mathbf{9}$, 13984.

[35] Tsai CL, Liang CS, Yang CP, Lee JT, Ho TH, Su MW, Lin GY, Lin YK, Chu HT, Hsu YW, Yang FC (2020) Indicators of rapid cognitive decline in amnestic mild cognitive impairment: The role of plasma biomarkers using magnetically labeled immunoassays. J Psychiatr Res 129, 66-72.

[36] Chang JF, Liu HC, Chen HH, Chen WP, Juang JL, Wang PN, Yang SY (2020) Effect of times to blood processing on the stability of blood proteins associated with dementia. Dement Geriatr Cogn Disord 49, 303-311.

[37] Yang SY, Chiu MJ, Chen TF, Lin CH, Jeng JS, Tang SC, Lee YF, Yang CC, Liu BH, Chen HH, Wu CC (2017) Analytical performance of reagent for assaying tau protein in human plasma and feasibility study screening neurodegenerative diseases. Sci Rep 7, 9304.

[38] Jiao F, Yi F, Wang Y, Zhang S, Guo Y, Du W, Gao Y, Ren J, Zhang H, Liu L, Song H, Wang L (2020) The validation of multifactor model of plasma Abeta 42 and total-tau in combination with MoCA for diagnosing probable Alzheimer disease. Front Aging Neurosci 12, 212.

[39] Lue LF, Sabbagh MN, Chiu MJ, Jing N, Snyder NL, Schmitz C, Guerra A, Belden CM, Chen TF, Yang CC, Yang SY, Walker DG, Chen K, Reiman EM (2017) Plasma levels of Abeta42 and tau identified probable Alzheimer's dementia: Findings in two cohorts. Front Aging Neurosci 9, 226.

[40] Lue LF, Pai MC, Chen TF, Hu CJ, Huang LK, Lin WC, Wu CC, Jeng JS, Blennow K, Sabbagh MN, Yan SH, Wang PN, Yang SY, Hatsuta H, Morimoto S, Takeda A, Itoh Y, Liu J, Xie H, Chiu MJ (2019) Age-dependent relationship between plasma Abeta40 and Abeta42 and total tau 
levels in cognitively normal subjects. Front Aging Neurosci 11, 222.

[41] Kivipelto M, Ngandu T, Laatikainen T, Winblad B, Soininen H, Tuomilehto J (2006) Risk score for the prediction of dementia risk in 20 years among middle aged people: A longitudinal, population-based study. Lancet Neurol 5, 735-741.

[42] Chen JH, Lin KP, Chen YC (2009) Risk factors for dementia. J Formos Med Assoc 108, 754-764.

[43] Norton S, Matthews FE, Barnes DE, Yaffe K, Brayne C (2014) Potential for primary prevention of Alzheimer's disease: An analysis of population-based data. Lancet Neurol 13, 788-794.

[44] Tsai PH, Liu JL, Lin KN, Chang CC, Pai MC, Wang WF, Huang JP, Hwang TJ, Wang PN (2018) Development and validation of a dementia screening tool for primary care in Taiwan: Brain Health Test. PLoS One 13, e0196214.
[45] Chang HY, Hsu CC, Pan WH, Liu WL, Cheng JY, Tseng CH, Bai CH, Yeh WT, Hurng BS (2010) Gender differences in trends in diabetes prevalence from 1993 to 2008 in Taiwan. Diabetes Res Clin Pract 90, 358-364.

[46] Chen DR, Frerichs LM (2014) Gender, social origins and accumulated disadvantages associated with mid-life body weight in Taiwan. Health 6, 2399-2407.

[47] Wang WS, Wahlqvist ML, Hsu CC, Chang HY, Chang WC, Chen CC (2012) Age- and gender-specific population attributable risks of metabolic disorders on all-cause and cardiovascular mortality in Taiwan. BMC Public Health $12,111$. 